\title{
AMBIVALÊNCIA DA POLÍTICA NO PRÓLOGO D'A CIDADE DE DEUS, DE AGOSTINHO
}

\author{
Luiz Marcos da Silva Filho'
}

\begin{abstract}
Resumo: No prólogo d'A cidade de Deus, Agostinho apresenta ambivalente concepção de política, pois a política adquire ou positividade ou negatividade conforme a identidade ou a contradição de uma civitas ou res publica consigo mesma. Mais precisamente, a cidade celeste, que guarda dois modos de existência, um na história, outro na eternidade, conquista progressivamente identidade na medida em que na história há processo coerente dela em direção a seu modo de existência por excelência, na eternidade; já a cidade terrena existe na história em contradição e conflito, ao tornar-se escrava da própria libido de dominação, de maneira que sua história é de progressiva danação e perda de ser. Uma cidade guarda, pois, estatuto político a despeito de sua orientação ou de sua desorientação moral. Além do mais, nos limites do prólogo, Agostinho explicita que o fundamento da política não é nem a natureza, nem a razão.

Palavras-chave: política - moral - história - eternidade - vontade.
\end{abstract}

No prólogo d'A cidade de Deus, Agostinho explicita que a concepção de política sobre a qual toda a obra versará é ambivalente, pois a política adquire positividade ou negatividade conforme a identidade ou a contradição de uma civitas ou res publica consigo mesma. Mais precisamente, a cidade celeste conquista progressivamente identidade na medida em que na história há processo coerente dela em direção a seu modo de existência por excelência, na eternidade, já a cidade terrena existe na história em contradição e conflito, ao tornar-se escrava da própria libido de dominação, de maneira que sua história é de progressiva perda de ser. Nossa análise procurará mostrar que o prólogo apresenta e problematiza os traços de identidade e de contradição constituintes de cada cidade segundo uma estrutura sintático-estilística conceitualmente orientada. Eis o primeiro período do prólogo.

A gloriosíssima cidade de Deus, tanto no curso dos tempos, enquanto peregrina entre os ímpios vivendo da fé, como na estabilidade da morada eterna, que agora espera com paciência, "até que a justiça se converta em juízo", e que depois será alcançada pela excelência na vitória final e paz perfeita, é a cidade que eu, na feitura desta obra, dívida de promessa que te fiz, caríssimo filho Marcelino, encarreguei-me de defender contra aqueles

\footnotetext{
1 Professor substituto de Filosofia no Departamento de Filosofia e Metodologia das Ciências da Universidade Federal de São Carlos - UFSCar. E-mail: lmarcosfilho@gmail.com.
} 
que preferem seus deuses ao Fundador dela: grande e árdua tarefa, mas

"Deus é nosso auxílio".

$\mathrm{Na}$ passagem, encontram-se traços de identidade da cidade celeste consigo mesma em dois registros, um na história, outro na eternidade. Os dois registros em que a identidade da "gloriosíssima cidade" celeste é apresentada são construídos por meio de duas expressões coordenadas, às quais orações se subordinam com o propósito de explicitar traços da cidade celeste em uma e na outra modalidade de existência. Tais observações sobre a estrutura sintático-estilística não são acessórias, pois revelam que Agostinho abre $A$ cidade de Deus em continuidade e ruptura com a épica clássica, com "o procedimento homérico, imitado por Vergílio e por tantos outros"3. De fato, $A$ cidade de Deus, como a Eneida, por exemplo, enuncia a matéria elevada que será cantada ("gloriosissimam civitatem del"; "arma virumque cano"), aquela sob a inspiração de Deus, esta, sob a das musas, logo nas primeiras palavras, em acusativo (objeto direto). O empreendimento agostiniano, todavia, não se confunde com o da épica antiga: logo após "salientar o que é essencial, prontamente interrompe a unidade e a claridade do período". Ora, entre "gloriosissimam civitatem del" e o esclarecimento do sujeito, que é Agostinho mesmo, escrevendo em primeira pessoa, apenas flagrado pelo verbo "suscepi”, encadeiam-se duas expressões coordenadas, sete orações subordinadas, entre as quais duas reduzidas, uma de particípio e a outra de infinitivo, além de apostos e um vocativo, explicitando-se tantos elementos problemáticos da investigação sobre a gloriosíssima cidade divina, que a clareza do tema das primeiras palavras é completamente turvada ${ }^{6}$.

2 "Gloriosissimam civitatem dei sive in hoc temporum cursu, cum inter impios peregrinatur ex fide vivens, sive in illa stabilitate sedis aeternae, quam nunc exspectat per patientiam, quoadusque iustitia convertatur in iudicium, deinceps adeptura per excellentiam victoria ultima et pace perfecta, hoc opere instituto et mea ad te promissione debito defendere adversus eos, qui conditori eius deos suos praeferunt, fili carissime Marcelline, suscepi, magnum opus et arduum, sed Deus adiutor noster est.". AUGUSTINUS, De civitate dei (Libri I-X), praefatio. Na ausência de menção, todas as traduções são de nossa responsabilidade.

${ }^{3}$ MOHRMANN, C. "Saint Augustin écrivain", p. 256.

${ }^{4}$ MOHRMANN, C. Op. cit., p. 256.

5 O superlativo gloriosissimus apresenta 14 reincidências ao longo da obra, sempre em referência à cidade de Deus (9) ou a cidadãos mártires (5). Trata-se de exigência do salmo 87 [86], 3, que diz "coisas gloriosas/gloriosíssimas são ditas de ti, cidade de Deus". Em seu comentário a esse salmo, proferido em 412, um ano antes do início da redação d'A cidade de Deus, Agostinho esclarece que a cidade referenciada pelo salmista é gloriosíssima porque universal e eterna, porque não se confunde com a Jerusalém terrena, que pereceu historicamente e era restrita a um único povo, os judeus. Em Enarrationes in Psalmos 86, 6, Agostinho cita pela primeira vez o versículo bíblico com o adjetivo gloriosa e termina citando o mesmo versículo com o superlativo gloriosissima. Em De civitate dei, X, vii, 7, a citação do salmo é realizada apenas no superlativo: Gloriosissima dicta sunt de te, civitas dei. Cf. COOPER, R. H.; FERRARI, L. C. Concordantia in XXII libros De ciuitate Dei S. Aurelii Augustini, p. 1177-8.

6 "A frase hipotática é entrecortada bruscamente para salientar um pensamento que preocupa o autor e que lhe parece essencial. Nada permanece do período bem construído e bem equilibrado. As frases incômodas e retorcidas mergulham-nos repentinamente nos problemas angustiantes que Agostinho vai discutir. Nesse 
Afinal, a civitas sobre a qual a obra versará guarda fundamento a-histórico, embora exista também na história. As duas expressões coordenadas que discernem os dois modos de existência, o do tempo e o da eternidade, são articuladas pela conjunção sive, em "sive [...] sive", cuja melhor tradução parece ser "tanto [...] como" por preservar o sentido de adição, não de oposição ou exclusão. Aliás, é comum a interpretação imprecisa de que a cidade celeste existe exclusivamente na eternidade e a terrena, no tempo histórico, de modo que neste ambas não estariam entretecidas (permixtae) ${ }^{8}$. Dessa forma, "a gloriosíssima cidade de Deus" existe "tanto no curso dos tempos [...], como na estabilidade da morada eterna". Assim, "no curso dos tempos", ela (1) peregrina em meio aos ímpios e (2) é vivificada pela fé. Já "na estabilidade da morada eterna”, é possível dizer indiretamente quais características a cidade possui, porque Agostinho continua anunciando traços da peregrinação histórica, mas apontando agora para o fim da história. Desse modo, pode-se dizer o que a cidade padece na história e o que espera deixar de padecer na eternidade. Mais precisamente, a cidade (1) espera a morada eterna "com paciência", (2) "até que a justiça se converta em juízo", e (3) depois alcançará essa morada "pela excelência na vitória final e paz perfeita".

Todas essas características da cidade celeste são complementares, pois a peregrinação "entre os ímpios" é impulsionada, vivificada, pela fé no horizonte a-histórico que a cidade acredita existir e alcançar progressivamente ${ }^{10}$. Antes disso, a cidade não está livre de perseguições e sofrimentos, em relação aos quais guarda paciência até o fim da história, isto é, até o Juízo Final, quando a justiça se tornará efetiva por meio do discernimento entre cristãos e ímpios, que não mais se encontrarão lado a lado como na história. Assim, na eternidade, a cidade divina não mais precisará suportar mal ou

Prólogo, Agostinho segue a regra da arte antiga que quer formular na primeira frase de uma obra o essencial de seu conteúdo. Ele o faz, porém, de uma maneira pouco tradicional, em suas frases incômodas que, por seus embaraços calculados, deixam-nos já entrever a imensidão dos problemas que o autor ousa penetrar. E essas primeiras frases são bem características do estilo de todos os livros De civitate Dei. A imensidão e a inescrutabilidade dos problemas tratados se refletem no aspecto atormentado do estilo com que o autor voluntariamente renunciou a toda facilidade elegante". MOHRMANN, C. Op. cit., p. 257.

7 “[...] sive... sive tem aqui, segundo uso frequente no latim tardio, o sentido de 'tanto... quanto/como' e não: 'seja... seja' (de Labriolle)". Ibid., p. $256^{25}$.

8 "[...] permixtae sunt ambae civitates". AUGUSTINUS, De civitate dei, XIX, xxvi.

9 AUGUSTINUS, De civitate dei, praefatio.

${ }^{10}$ Sobre a controversa discussão sobre o conceito de "progresso" no pensamento agostiniano, cf. ADORNO, T. W. "Progresso"; ARCHAMBAULT, P. "The Ages of Man and the Ages of the World, A Study of two Traditions"; BREZZI, P. "Una civitas terrena spiritualis come ideale storico-politico di Sant'Agostino"; CHAXRUY, J. Saint Augustin - Temps et Histoire; GILSON, É. Evolução da Cidade de Deus; GÜNTHER, H. Le temps de l'histoire - Expérience du monde et catégories temporelles en philosophie de l'histoire de saint Augustin à Petrarque, de Dante à Rousseau; HARTOG, F. A História - de Homero a santo Agostinho; LIGOTA, C. "La foi historienne"; MARKUS, R. A. Saeculum: History and Society in the Theology of St Augustine; MARROU, HI. L'ambivalence du temps de l'bistoire chez. saint Augustin; TH. "St. Augustine and the Christian Idea of Progress". "La théologie de l'histoire"; MOMMSEN, 
sofrimento algum, de forma que a paciência não terá razão de existir em uma realidade em que a civitas haverá alcançado seu modo de existência por excelência, o de plena identidade, com "vitória final e paz perfeita", porque não haverá nada contra que combater nem a que resistir.

$\mathrm{Na}$ continuidade do prólogo, Agostinho diz que é essa a cidade que ele se encarregou "de defender contra aqueles que preferem seus deuses ao Fundador dela". A referência é aos já mencionados ímpios, de forma que a posição de Agostinho é a de cidadão da cidade divina que fiel e pacientemente combate aqueles que, ao negar o verdadeiro fundamento, precipitam-se no histórico. A tarefa é "grande e árdua" e exige o auxílio de Deus porque se trata de defender dos ímpios uma realidade transcendente e presente, com todas as suas características, conforme seus modos de existência histórico e a-histórico.

A defesa da gloriosíssima cidade, porém, não se dá em função de qualquer ameaça que os ímpios possam representar a ela. Afinal, a cidade cujo fundador é o próprio absoluto é inabalável e nunca poderia ser assaltada por aqueles que supõem impulsionar-se a partir de falso e relativo fundamento, a saber, os deuses pagãos. Por que, então, empreender obra monumental como $A$ cidade de Deus contra os pagãos? Nos limites do que o prólogo revela, em primeiro lugar para elucidar por meio de exegese bíblica e reflexão filosófica a realidade em que os cristãos guardam fé, de maneira a impulsionar a inteligência de uma realidade invisível ou parcialmente visível, porque sua excelência e a "vitória final e paz perfeita" não podem ser comportadas pelo tempo histórico. Em segundo lugar, porque os pagãos, se não ameaçam a excelsa cidade, são ameaça para si mesmos ao pretender usurpar a grandeza divina com tal soberba, com a qual não enxergam a vulnerabilidade de seus projetos e de seus deuses, a mentira que erroneamente tomam como verdade, o caminho e o horizonte de contradição, de conflito e de precipitação pelo qual e ao qual são conduzidos.

Assim, o empreendimento de defender dos pagãos a gloriosíssima cidade cumprirá a estratégia de elucidar em vários planos a identidade e a contradição a que se encaminham, respectivamente, a cidade de Deus e os pagãos. A continuidade do prólogo trata, aliás, precisamente da presunção, da mentira, da contradição e do conflito que são traços dos soberbos e da cidade terrena, que será pela primeira vez mencionada na obra apenas no quinto e último período do prólogo. Antes, porém, após dizer que a defesa da cidade divina é tarefa "grande e árdua", Agostinho explica:

Pois estou ciente dos esforços necessários para persuadir os soberbos da grandeza da virtude da humildade, cuja celsitude, não usurpada pela altivez 
humana, mas concedida pela graça divina, transcende todas as culminâncias terrenas, instáveis na mobilidade do tempo. ${ }^{11}$

Agostinho pretende persuadir os soberbos de que eles não realizam aquilo que projetam, porque a grandeza da virtude que almejam não pode ser obtida pelo modo como a buscam nem no lugar em que a buscam. Mais precisamente, trata-se de demovê-los da ilusão de que a iniciativa humana, terrena, seja capaz de alcançar a celsitude, de que um projeto de grandeza possa ter êxito em uma realidade marcada pela dispersão. Ao contrário, a verdadeira grandeza da virtude não pode ser conquistada pelo homem por si mesmo, pois ela apenas pode ser dada a ele, gratuitamente, a partir da iniciativa divina.

A virtude em questão, todavia, é a humildade, antônimo da soberba, em relação às quais o céu e a terra são dispostos como seus respectivos loci. Aliás, todo o segundo período, como o prólogo por inteiro, é construído por meio de antíteses e paradoxos que dispõem em relações de oposição um vocabulário referente a grandes e a pequenas altitudes subvertendo seus significados ${ }^{12}$, notadamente em relação à imanência ou à terra, onde as grandes altitudes ("terrena cacumina") não oferecem passagem à transcendência ou ao céu/celsitude, apenas acessível das pequenas altitudes, em que se encontram aqueles que, com humildade, reconhecem o fracasso do projeto humano de autossuficiência e, sobretudo, a necessidade de socorro divino.

Afinal, o rei e fundador desta cidade, da qual nos propusemos a falar, revelou nas Escrituras de seu povo uma máxima da lei divina: Deus resiste aos soberbos, mas dá graça aos bumildes ${ }^{13}(\operatorname{Pr} 3,34 ; \operatorname{Tg} 4,6 ; 1 \operatorname{Pd} 5,5)$.

A lei divina expressa pela citação bíblica retoma em patamar elevado a relação com o divino, cindida pelo vício da soberba e restaurada pela virtude da humildade. Mas qual é o sentido de lex divina? Se se trata de lex divina, certa noção de iustitia está presente e é o que explica por que Deus resiste aos soberbos, mas dá graça aos bumildes. Ora, a justiça é a virtude,

\footnotetext{
11 "Nam scio quibus viribus opus sit, ut persuadeatur superbis quanta sit virtus bumilitatis, qua fit ut omnia terrena cacumina temporali mobilitate nutantia non humano usurpata fastu, sed divina gratia donata celsitudo transcendat.". AUGUSTINUS, De civitate dei, praefatio.

12 "É próprio da humildade (coisa maravilhosa!) elevar o coração, e exclusivo da soberba abaixá-lo. Ao parecer, é paradoxo que a soberba desça e a humildade suba. Mas acontece que a humildade piedosa nos submete ao superior e nada há superior a Deus; por isso a humildade que nos submete a Deus exalta-nos." (Tradução de Oscar Paes Leme). "Est igitur aliquid bumilitatis miro modo quod sursum faciat cor, et est aliquid elationis quod deorsum faciat cor. Hoc quidem quasi contrarium videtur, ut elation sit deorsum et humilitas sursum. Sed pia humilitas facit subditum superiori; nibil est autem superius Deo; et ideo exaltat humilitas, quae facit subditum Deo.". Ibid., XIV, xiii, 1. 13 "Rex enim et conditor civitatis huius, de qua loqui instituimus, in Scriptura populi sui sententiam divinae legis aperuit, qua dictum est: Deus superbis resistit, humilibus autem dat gratiam.". Ibid., loc. cit.
} 
absoluta em Deus, que dá a cada um o que lhe é devido". Assim, "justiça" e "ordem" são indissociáveis e constituem o sentido de "lei divina", pois há ordem justa quando o inferior se submete ao superior e o superior impera sobre o inferior ${ }^{16}$. Por consequência, quando o homem abandona seu princípio e pretende fazer-se princípio para si mesmo e sêlo, com justiça Deus resiste à criatura soberba e injusta ${ }^{17}$. Inversamente, quando o homem ama menos a si mesmo e as criaturas do que a Deus, ou ama a si mesmo e elas Nele, a participação ontológica, ou ordem justa, entre Criador e criatura não é fraturada, o que é uma das formas de entender-se por que Deus dá graças aos humildes.

Além disso, o terceiro período do prólogo fornece elementos sobre o ordenamento da cidade, até agora apresentada conforme características ontológicas, morais e políticas que não se referem a instituições ou formas de governo sem as quais ela inexistiria. Aqui, todavia, certo vocabulário da tradição política romana é mobilizado no momento em que Deus é apresentado como o "rei e fundador" da cidade. Uma leitura apressada poderia enxergar aí que "Agostinho foi o fundador do ideal teocrático medieval"18. Mais elementos, todavia, são precisos para tanto, como o discernimento de uma ou mais instituições com autoridade e poder para estabelecer na história leis temporais em adequação com a lei divina. Seja como for, "embora ele jamais tenha formulado o princípio de um governo teocrático, a ideia não é inconciliável com sua doutrina, pois, se o ideal da Cidade de Deus não implica essa ideia, não a exclui." ${ }^{\text {"19 }}$.

O quarto período do prólogo conduz o leitor para a compreensão de que a referência a Deus a partir de vocabulário da tradição política ${ }^{20}$ tem menos o intuito de refletir sobre uma forma de governo da cidade celeste e mais o de conferir desenvolvimento ao problema das iniciativas humana e divina em relação à soberba e à

\footnotetext{
14 "Quid iustitia, cuius munus est sua cuique tribuere". Ibid., XIX, iv, 4. Cf. ibid., XIX, xxi, 1.

15 "Ut igitur breviter aeternae legis notionem, quae impressa nobis est, quantum valeo verbis explicem, ea est qua iustum est ut omnia sint ordinatissima". Id., De libero arbitrio libri tres, I, vi, 15.

16 "Deus homini, animus imperat corpori, ratio libidini ceterisque vitiosis animi partibus". Id., De civitate dei, XIX, xxi, 2.

17 "E que é a soberba, senão apetite de celsitude perversa? A celsitude perversa consiste em abandonar o princípio a que o ânimo deve estar unido e fazer-se de certa maneira princípio para si e sê-lo. É o que acontece quando o espírito se agrada em demasia de si mesmo e agrada-se em demasia de si mesmo quando declina do bem imutável, que deve agradar-lhe mais do que ele a si mesmo." (Tradução de Oscar Paes Leme). "Quid est autem superbia nisi perversae celsitudinis appetitus? Perversa enim est celsitudo deserto eo, cui debet animus inhaerere, principio sibi quodam modo fieri atque esse principium. Hoc fit, cum sibi nimis placet. Sibi vero ita placet, cum ab illo bono inmutabili deficit, quod ei magis placere debuit quam ipse sibi.". Ibid., XIV, xiii, 1.

18 "Augustine was the originator of the mediaeval theocratic ideal". DAWSON, C. "St. Augustine and his Age", apud PARKER, Th.-M. "St. Augustine and the Conception of Unitary Sovereignty", p. 951.

${ }^{19}$ GILSON, É. Introdução ao estudo de santo Agostinho, p. 346.

${ }^{20}$ Cf. AUGUSTINUS, De civitate dei, XXII, vi, onde há comparação entre Cristo e Rômulo como fundadores. Veja-se breve comentário que tecemos a respeito na "Nota sobre os conceitos de 'fundação', fides e salus em Cícero e Agostinho", presente em nossa Dissertação de Mestrado: SILVA FILHO, L. M. A definição de populus n'A cidade de Deus de Agostinho: uma controvérsia com Da república de Cícero. Cf. também HEYKING, John von. Augustine and politics as longing in the world, p. 71-6.
} 
humildade, que foi disposto nos segundo e terceiro períodos. De outro modo, o movimento do texto, se aponta para apropriação agostiniana certo vocabulário do republicanismo antigo, é para indicar sobretudo que os soberbos cometeram falta de injustiça porque usurparam o exclusivo estatuto divino de legislador e governante do mundo. Eis o quarto período: "Efetivamente, o espírito inchado de soberba quer apoderarse do que pertence a Deus e ama que proclamem em seu louvor: Poupar os vencidos e subjugar os soberbos." ${ }^{21}$. Não à toa, a antítese entre a citação do terceiro período e a do quarto é expressa por meio do contraste entre uma bíblica e uma pagã, a primeira em referência à iniciativa divina e à humildade, a segunda, à iniciativa humana e à soberba. Além disso, o inchaço da soberba proporciona ao espírito certa cegueira ${ }^{22}$, que o impede de enxergar que a iniciativa de vanglória é contraproducente, pois a celsitude desejada se torna ainda mais distante, em função da tentativa de conquistá-la por meio da altivez humana ${ }^{23}$.

Finalmente, o quinto e último período do prólogo apresenta pela primeira vez a cidade terrena nominalmente, explicitando o que impulsiona o soberbo à iniciativa de vanglória e o seu efeito contraproducente.

Por isso, também a respeito da cidade terrena -, que com o desejo de dominar, e não obstante povos sejam seus escravos, é dominada pela própria libido de dominação -, não deixarei passar em silêncio tudo aquilo que o plano desta obra exigir e a minha capacidade permitir dizer. ${ }^{24}$

Aqui, como no primeiro período, após enunciar a cidade de que se trata, o autor apresenta seus traços de existência ${ }^{25}$. Diferentemente da cidade celeste, a terrena é exposta somente em registro histórico e não em processo de identidade ou em plena identidade, mas em contradição consigo mesma. Segundo Jean-Claude Guy, a contradição se dá porque nela há uma "heterogeneidade entre o que é projetado e o que é realizado"26, como, aliás, apontávamos no segundo período, na medida em que, por meio do projeto de

21 "Hoc vero, quod Dei est, superbae quoque animae spiritus inflatus adfectat amatque sibi in laudibus dici: Parcere subiectis et debellare superbos" (Eneida, VI, 853). AUGUSTINUS, De civitate dei, praefatio.

22 “[...] tumore meo separabar abs te et nimis inflata facies claudebat oculos meos.". Id., Confessionum libri tredecim, VII, vii, 11.

23 "Quid est autem superbia nisi perversae celsitudinis appetitus?". Ibid., XIV, xiii.

24 "Unde etiam de terrena civitate, quae cum dominari adpetit, etsi populi serviant, ipsa ei dominandi libido dominatur, non est praetereundum silentio quidquid dicere suscepti huius operis ratio postulat si facultas datur.". AUGUSTINUS, De civitate dei, praefatio.

25 "Como a Civitas Dei na primeira frase, aqui é a terrena civitas que é destacada; novamente aqui a tendência em colocar o acento sobre o que é o elemento essencial da Cidade (a dominandi libido) rompe a estrutura normal da frase. Nesses dois períodos essenciais do Prólogo, santo Agostinho nos dá um espécime de arte que, inteiramente em semelhança com os elementos estilísticos mais tradicionais, é novo pela ousadia com a qual ele rompe com a tradição do período clássica.". MOHRMANN, C. "Saint Augustin écrivain", p. 257-258.

${ }^{26}$ GUY, J-C. Unité et structure logique de la "Cité de Dieu” de saint Augustin, p. 30. Grifo do autor. 
dominação, ela "não só não realiza o que se propõe a realizar; mas realiza o contrário mesmo do que acredita realizar ${ }^{27}$ : torna-se escrava da própria libido de dominação.

Em suma, após examinar os principais traços de ambas as cidades presentes no prólogo d'A cidade de Deus, pode-se dizer que Agostinho desde o início da obra revela ambivalência e desnaturalização da política. Com efeito, para o autor, a política parece guardar positividade ou negatividade, conforme a realização dela preserve ou não a natureza humana. Ainda que não enunciada com todas as letras, toda a discussão sobre a humildade e a soberba trata da identidade presente no homem por natureza e da contradição nele introduzida em condição pecaminosa ${ }^{28}$. Daí decorre a possibilidade de uma cidade possuir estatuto político independente da moral e da realização da natureza.

Ora, tanto a cidade celeste, quanto a terrena, possuem estatuto político. A despeito do traço de identidade de uma e do de contradição da outra, ambas são cidades ou repúblicas e possuem os respectivos povos. Isso quer dizer que, para Agostinho, um conjunto de homens pode guardar estatuto político, estatuto de "povo", ainda que moralmente desorientado, de maneira que o critério agostiniano para conferir estatuto político a uma multitudo não é moral. Além disso, se para o autor um conjunto de homens moralmente desorientado é multitudo danada, na qual a investigação agostiniana, ao nela flagrar traços de contradição, pretende encontrar homens apartados de sua natureza e identidade, então a possibilidade de "política" e "moral" não coexistirem em uma "república" repousa em fundamento da política que não é a natureza.

Assim, se podemos falar de ambivalência e desnaturalização da política em Agostinho, que concede à política autonomia em relação à moral, certamente seu propósito, como vimos no prólogo, não é conferir positividade a uma política divorciada da moral, como talvez seja o projeto de um autor moderno, como Maquiavel. Desse modo, por que conferir estatuto político a um conjunto de homens moralmente desorientados? Por que dizer que homens depravados constituem "povo"? Por que Agostinho não procede como Cícero, que em sua obra Da república, concede estatuto político não a toda e qualquer multitudo, mas apenas àquela que cumpre duas condições, quais sejam, iuris consensus e utilitatis communio ${ }^{29}$, as quais exigem observância da moral, da natureza e da razão?

27 GUY, J-C. Op. cit., loc. cit. Grifo do autor.

${ }^{28}$ Sobre a distinção agostiniana entre natureza e condição humana, cf. A cidade de Deus, XIV, i; XIX, xv, onde talvez haja uma das referências mais explícitas a respeito.

29 “[...] povo é não toda união de homens de qualquer modo congregados, mas a união de inumeráveis homens associados por assentimento de direito e utilidade comum". "[...] populus [autem] non omnis hominum coetus quoquo modo congregatus, coetum multitudinis iuris consensu et utilitatis communione sociatum". CICERO, De re publica, I, xxv, 39 . 
Antes de responder, pretendemos aqui indicar que encontramos no prólogo o projeto de reflexão política d'A cidade de Deus, que não à toa precisará de dezenove livros para gestar uma definição de populus em ruptura com a ciceroniana, notadamente por destituí-la de critério moral e jurídico para discernir qual multidão pode candidatar-se a formar uma res publica: "Povo é o conjunto de inumeráveis seres racionais associado pela concorde comunhão de coisas que amam"30.

\section{THE AMBIVALENCE OF POLITICS IN THE AUGUSTINE'S PROLOGUE OF THE CITY OF GOD}

Abstract: In the City of God's prologue, Augustine shows an ambivalent conception of politics, because the politics acquires positivity or negativity according to the identity or contradiction of a civitas or res publica with itself. More precisely, the celestial city, which has two modes of existence, one in the history, other in the eternity, progressively conquers identity as in history succeeds a coherent process towards its genuine mode of existence, in eternity. On the other hand, the earthly city exists in the history in contradiction and conflict in becoming slave of its own libidinousness of dominance so that its history is one of a progressive damnation and lost of being. Therefore a city holds political statute in despite of its moral orientation or disorientation. Moreover, within the limits of the prologue, the Augustinian foundation of politics is neither the nature nor the reason. Keywords: politics - morals - history - Eternity - will.

\section{Referências Bibliográficas}

\section{Fontes primárias:}

AUGUSTINUS. De civitate dei (Libri I-X). Corpus Christianorum Series Latina XLVII. Turnhout: Brepols, 1955.

De civitate dei (Libri XI-XXII). Corpus Christianorum Series Latina XLVIII. Turnhout: Brepols, 1955.

Confessionum libri tredecim. Patrologia Latina Tomus 32. Turnhout: Brepols, 1992.

De libero arbitrio libri tres. Patrologia Latina Tomus 32. Turnhout: Brepols, 1992.

A cidade de Deus. (contra os pagãos). 2 volumes. Trad. Oscar Paes Leme. Petrópolis: Vozes,

30 "Populus est coetus multitudinis rationalis rerum quas diligit concordi communione sociatus". AUGUSTINUS, De civitate dei, XIX, xxiv. 
CICERO. De re publica. Leipzig: Bibliotheca Scriptorum Graecorum et Romanorum Teubneriana, 1964.

Fontes secundárias:

ADAMS, J. D. “Augustine’s Definitions of Populus and the Value of Civil Society”. In:

DONNELLY, D. F. The City of God - A Collection of Critical Essays. New York: PETER LANG, 1995, p. 171-182.

ADORNO, T. W. "Progresso”. Trad. Cohn, G. Lua Nova 27 (1992), p. 217-236.

ARCHAMBAULT, P. "The Ages of Man and the Ages of the World, A Study of two Traditions", Revue des Études Augustiniennes 12 (1966), p. 193-228.

BREZZI, P. "Una civitas terrena spiritualis come ideale storico-politico di Sant'Agostino", Augustinus Magister, II, Paris, 1954, p. 915-922.

CHAX-RUY, J. Saint Augustin - Temps et Histoire. Paris: Études Augustiniennes, 1956.

COOPER, R. H.; FERRARI, L. C. Concordantia in XXII libros De ciuitate Dei S. Aurelii Augustini. Hildesheim: Olms-Weidmann, 1999.

GILSON, É. Evolução da Cidade de Deus. São Paulo: Herder, 1965.

Introdução ao estudo de santo Agostinho. Trad. Ayoub, C. N. A. São Paulo: Discurso Editorial; Paulus, 2006.

GÜNTHER, H. Le temps de l'histoire - Expérience du monde et catégories temporelles en philosophie de l'histoire de saint Augustin à Petrarque, de Dante à Rousseau. Paris: Éditions de la Maison des Sciences de l'Homme, 1996.

GUY, J-C. Unité et structure logique de la "Cité de Dieu”de saint Augustin. Paris: Études Augustiniennes, 1961.

HARTOG, F. A História - de Homero a santo Agostinho. Belo Horizonte: UFMG, 2001.

HEYKING, John von. Augustine and politics as longing in the world. Columbia: University of Missouri Press, 2001.

LIGOTA, C. “La foi historienne”, Revue des Études Augustiniennes, 43 (1997), p. 111-171. 
MARKUS, R. A. Saeculum: History and Society in the Theology of St Augustine. Cambridge: Cambridge University Press, 1970.

MARROU, H-I. L'ambivalence du temps de l'bistoire chez saint Augustin. Montréal-Paris: Vrin, 1950.

"La théologie de l'histoire", Augustinus Magister, III, Paris, 1954, p. 193-212.

MOHRMANN, C. "Saint Augustin écrivain". In: Études sur le latin des Chrétiens, Tome II - Latin cbrétien et médiéval. Roma: Edizioni di Storia e Letteratura, 1961.

MOMMSEN, TH. "St. Augustine and the Christian Idea of Progress", Journal of the History of Ideas XII (1951), p. 346-374.

PARKER, Th.-M. "St. Augustine and the Conception of Unitary Sovereignty", Augustinus Magister, II, Paris, 1954, p. 951-955.

SILVA FILHO, L. M. A definição de populus n'A cidade de Deus de Agostinho: uma controvérsia com Da república de Cícero. Dissertação de Mestrado em Filosofia, São Paulo, USP, 2008.

Desnaturalização da política n'A cidade de Deus, de Agostinho. Tese de Doutorado em Filosofia, São Paulo, USP, 2012. 


\title{
Apêndice I: Ensaio de tradução do prólogo d'A cidade de Deus
}

\author{
De civitate dei \\ Sobre/A cidade de Deus
}

\section{Praefatio. De suscepti operis consilio et argumento Prefácio. A propósito do plano e assunto da obra executada}

1 - Gloriosissimam civitatem Dei sive in hoc temporum cursu, cum inter impios peregrinatur ex fide vivens, sive in illa stabilitate sedis aeternae, quam nunc exspectat per patientiam, quoadusque iustitia convertatur in iudicium, deinceps adeptura per excellentiam victoria ultima et pace perfecta, hoc opere instituto et mea ad te promissione debito defendere adversus eos, qui conditori eius deos suos praeferunt, fili carissime Marcelline, suscepi, magnum opus et arduum, sed Deus adiutor noster est.

1 - A gloriosíssima cidade de Deus (cf. Sl 87 [86], 3), tanto no curso dos tempos, enquanto peregrina entre os ímpios vivendo da fé (cf. Hab 2, 4), como na estabilidade da morada eterna, que agora espera com paciência (cf. Rm 8, 25), até que a justica se converta em juízo (S1 94 [93], 15), e que depois será alcançada pela excelência na vitória final e paz perfeita, é a cidade que eu, na feitura desta obra, dívida de promessa que te fiz, caríssimo filho Marcelino, encarreguei-me de defender contra aqueles que preferem seus deuses ao Fundador dela: grande e árdua tarefa, mas Deus é nosso auxilio (S1 62 [61], 9).

2 - Nam scio quibus viribus opus sit, ut persuadeatur superbis quanta sit virtus bumilitatis, qua fit ut omnia terrena cacumina temporali mobilitate nutantia non bumano usurpata fastu, sed divina gratia donata celsitudo transcendat.

2 - Pois estou ciente dos esforços necessários, para persuadir os soberbos da grandeza da virtude da humildade, cuja celsitude, não usurpada pela altivez humana, mas concedida pela graça divina, transcende todas as culminâncias terrenas, instáveis na mobilidade do tempo.

3 - Rex enim et conditor civitatis buius, de qua loqui instituimus, in Scriptura populi sui sententiam divinae legis aperuit, qua dictum est: Deus superbis resistit, humilibus autem dat gratiam.

3 - Afinal, o rei e fundador desta cidade, da qual nos propusemos a falar, revelou nas Escrituras de seu povo uma máxima da lei divina: Deus resiste aos soberbos, mas dá graça aos humildes ( $\operatorname{Pr} 3,34 ; \operatorname{Tg} 4,6$; $1 \mathrm{Pd} 5,5)$. 
4 - Hoc vero, quod Dei est, superbae quoque animae spiritus inflatus adfectat amatque sibi in laudibus dici: Parcere subiectis et debellare superbos (Eneida, VI, 853).

4 - Efetivamente, o espírito inchado de soberba quer apoderar-se do que pertence a Deus e ama que proclamem em seu louvor: Poupar os vencidos e subjugar os soberbos.

5 - Unde etiam de terrena civitate, quae cum dominari adpetit, etsi populi serviant, ipsa ei dominandi libido dominatur, non est praetereundum silentio quidquid dicere suscepti buius operis ratio postulat si facultas datur.

5 - Por isso também a respeito da cidade terrena -, que com o desejo de dominar, e não obstante povos sejam seus escravos, é dominada pela própria libido de dominação -, não deverei passar em silêncio tudo aquilo que o plano desta obra exigir e a minha capacidade permitir dizer. 


\section{Apêndice II: Ensaio de diagrama sintático-estilístico (AUGUSTINUS, De civitate Dei, praefatio)}

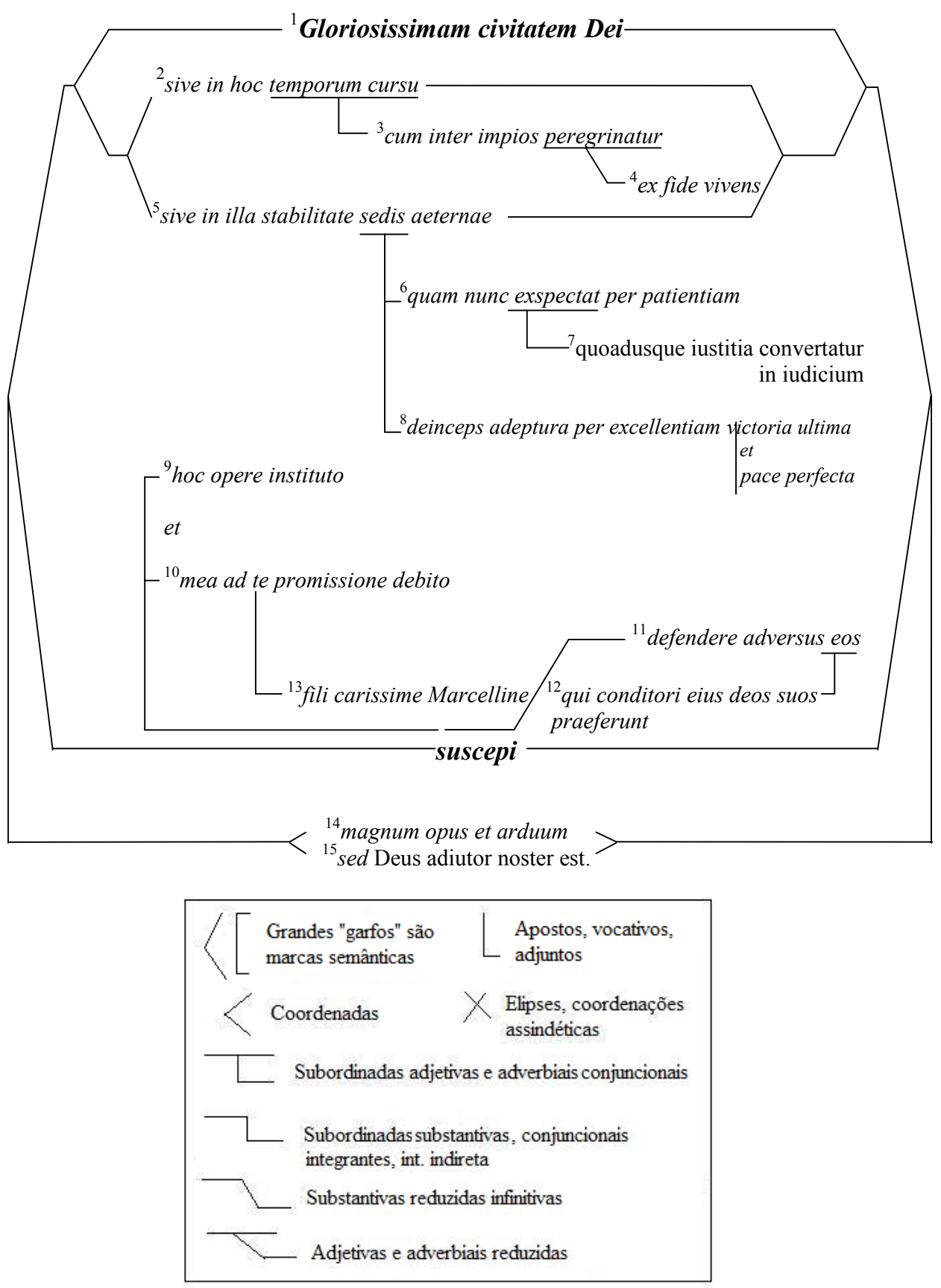

